\title{
SISTEM PENDUKUNG KEPUTUSAN PEMBERIAN BERAS UNTUK KELUARGA MISKIN DENGAN METODE SIMPLE ADDITIVE WEIGHTING
}

\author{
Jamal Abdul Nasir \\ Sistem Informasi \\ STMIK Nusa Mandiri Jakarta \\ www.nusamandiri.ac.id \\ jamalabdul66@gmail.com
}

\begin{abstract}
To improve Indonesia's economic stability, the Government has tried various methods. One of the policies taken by the government is to issue a RASKIN (Rice for the Poor) policy. In the distribution of Raskin there are often obstacles or problems, one of which is the leveling of the amount of Raskin received by all recipients and the misdirected distribution of rice. Decision support systems are part of overcoming these problems so a study was made to develop a computer application that helps make a decision. The subject of this research was the application of the decision support system for selection of Raskin acceptance using the Simple Additive Weighting (SAW) method. The purpose of this study as an alternative to assist the RT management in determining decisions related to the provision of Raskin rice for residents in accordance with the requirements and criteria of the RT 04 RW.01 Sukmajaya Depok administration.
\end{abstract}

\section{Keywords: Simple Additive Weighting, RASKIN, Decision Support System}

Abstrak - Untuk memperbaiki stabilitas ekonomi Indonesia, Pemerintah mengupayakan berbagai cara. Salah satu kebijakan yang diambil pemerintah yaitu dengan mengeluarkan kebijakan RASKIN (Beras Untuk Masyarakat Miskin). Dalam pendistribusian Raskin sering kali ditemui kendala atau permasalahan, salah satunya adanya penyamarataan jumlah Raskin yang diterima oleh semua penerima dan pembagian beras yang salah sasaran. Sistem pendukung keputusan merupakan bagian untuk mengatasi masalah tersebut maka dibuat sebuah penelitian untuk mengembangkan suatu aplikasi komputer yang membantu mengambil sebuah keputusan. Subjek pada penelitian ini adalah aplikasi Sistem Pendukung Keputusan seleksi penerimaan raskin menggunakan metode Simple Additive Weighting (SAW). Tujuan penelitian ini sebagai salah satu alternatif untuk membantu kepengurusan RT dalam menentukan keputusan terkait pemberian beras raskin bagi warga sesuai dengan syarat dan kriteria pengurus RT 04 RW.01 Kelurahan Sukmajaya Depok.

Kata Kunci: Simple Additive Weighting, RASKIN, Sistem Pendukung Keputusan

\section{PENDAHULUAN}

Indonesia merupakan negara agraris, ratarata penghasilan didapat dari pertanian. Salah satu bidang pertanian yang paling maju adalah padi, yang menghasilkan beras sebagai makanan pokok. Banyaknya warga negara Indonesia, menyebabkan hasil panen beras dalam negeri tidak cukup untuk memenuhi kebutuhan warganya (Rini \& Soyusiawaty, 2014), sehingga memerlukan tambahan pasokan dari luar negeri. Hal ini menyebabkan terjadinya kekurangan bahan pangan (Widiarsih, 1974) terutama pada keluarga tidak mampu.

Untuk memperbaiki stabilitas ekonomi Indonesia, Pemerintah mengupayakan berbagai cara. Salah satu kebijakan yang diambil pemerintah yaitu dengan mengeluarkan kebijakan RASKIN (Beras Untuk Masyarakat Miskin). Dalam pendistribusian Raskin sering kali ditemui kendala atau permasalahan, salah satunya adanya penyamarataan jumlah Raskin yang diterima oleh semua penerima Raskin (Angrawati, Angrawati, Yamin, \& Ransi, 2016). Masih terjadi kecurangan dalam pemilihan masyarakat calon penerima RASKIN (Handayani, 2016). Sementara ada derajat sosial yang berbeda antara sesama penerima Raskin tersebut. Derajat sosial ini terutama dipengaruhi oleh tingkat pendapatan dan jenis profesi atau sumber mata pencaharian para penerima Raskin. dilingkungan RT.04 RW.01 Kelurahan Sukmajaya merupakan sebuah pemerintahan level paling bawah pada suatu sistem pemerintahan yang terletak di Kecamatan Sukmajaya Depok. Warga di RT.04 RW.01 ini berasal dari berbagai daerah di Indonesia. Dengan jumlah Kepala Keluarga sebanyak 250 kepala keluarga (KK).

Dalam pengambilan keputusan untuk menentukan kriteria keluarga miskin dibutuhkan 
sebuah sistem informasi yang dapat membantu mengatasi kecurangan yang dilakukan oleh pihak tertentu dalam menentukan calon penerima raskin. Sistem pendukung keputusan merupakan bagian dari sistem informasi berbasis komputer yang mengatasi masalah ini. Sistem ini dapat mendukung pengambilan keputusan calon penerima raskin berdasarkan kriteria-kriteria yang telah ditentukan. Cara kerja sistem ini mencakup seluruh tahap pengambilan masalah, memilih data yang relevan dan menentukan pendekatan yang digunakan dalam proses pengambilan keputusan sampai pemecahan dan solusi masalah.

Beras untuk keluarga miskin atau raskin merupakan program pemerintah dalam menanggulangi kemiskinan. Program raskin ini bertujuan untuk membantu kelompok miskin dan rentan miskin mendapat cukup pangan dan nutrisi karbohidrat tanpa terkendala (Marlaeni \& Satria, 2017). Namun dalam pelaksanaan raskin ini banyak masalah, diantara masalah tersebut adalah pembagian beras yang salah sasaran (Septian, Bahri, \& Makmur, 2013), untuk mengatasi masalah tersebut maka dibuat sebuah penelitian untuk mengembangkan suatu aplikasi komputer yang membantu mengambil sebuah keputusan. Subjek pada penelitian ini adalah aplikasi Sistem Pendukung Keputusan seleksi penerimaan raskin menggunakan metode Simple Additive Weighting (Suryeni, Agustin, \& Nurfitria, 2015). Metode penggumpulan data dengan literatur, dokumentasi, wawancara. Tahap pengembangan aplikasi meliputi perancangan interface, analisis, pembuatan diagram konteks, diagram alir data, Entity Realationship Diagram, mapping table, rancangan tabel, perancangan menu dan antarmuka, implementasi dan pengujian, metode yang digunakan adalah metode Simple Additive Weighting dan pengujian sistem menggunakan blackbox test dan alpha test.

Dari penelitian yang menghasilkan sebuah perangkat lunak sistem pendukung keputusan seleksi penerimaan raskin menggunakan metode Simple Additive Weighting dengan kemampuan dapat membantu menyeleksi warga berdasarkan kriteria-kriteria kondisi rumah, pekerjaan, penghasilan, jumlah tanggungan, asset pribadi. Informasi yang dihasilkan adalah warga layak dan tidak layak menerima beras. Hasil uji coba menunjukkan bahwa aplikasi ini layak dan dapat digunakan. (Rini dan Soyusiawaty 2014:2)

Tujuan penelitian ini sebagai salah satu alternatif untuk membantu kepengurusan RT dalam menentukan keputusan terkait pemberian beras raskin bagi warga sesuai dengan syarat dan kriteria pengurus RT 04 RW.01 Kelurahan Sukmajaya Depok. Melakukan penilaian dari setiap kriteria untuk pemberian beras raskin. Menerapakan metode Simple Additive Weighting (SAW) dalam menentukan pemberian beras raskin untuk warga RT.04 RW.01 Kelurahan Sukmajaya Depok. Merancang suatu Sitem Pendukung Keputusan pemberian beras raskin yang memenuhi syarat dan kriteria dengan cepat dengan kebutuhan pengurus RT.04 RW.01 Kelurahan Sukmajaya Depok.

\section{METODE PENELITIAN}

\section{A. Tahapan Penelitian}

Dalam hal ini akan diuraikan mengenai langkah langkah yang akan dilakukan untuk mendapatkan metodologi penlitian yang merupakan suatu tahapan yang harus diterapkan agar penilitian dapat dilakukan dengan terarah dan memudahkan dalam melakukan analisa terhadap permasalahan yang ada.

Tahapan penelitian tentang Sistem Pendukung Keputusan Pemberian Beras Untuk Keluarga Miskin Dengan Metode Simple Additive Weighting (SAW) dijelaskan secara umum sebagai berikut:

\section{Survey Literatur}

Dalam tahap ini peneliti melakukan pengumpulan bahan literatur dan informasi terkait.

\section{Identifikasi Masalah}

Mengidentifikasi masalah yang akan dibahas, berkaitan dengan Sistem Pendukung Keputusan Pemberian Beras Untuk Keluarga Miskin Dengan Metode Simple Additive Weighting (SAW) sesuai dengan literature dan informasi yang diperoleh.

\section{Studi Pustaka}

Peneliti mempelajari buku-buku, jurnal penelitian, dan e-book teori tentang sistem pendukung keputusan dan metode Simple Addictive weighting (SAW) yang akan digunakan sebagai kajian teori dalam penelitian.

\section{Hipotesis}

Peneliti memiliki hipotesis awal, yaitu diduga dalam pengambilan keputusan dengan menggunakan Simple Additive Weighting (SAW) akan memberikan alternatif keputusan yang baik bagi pengurus RT.04/01 sehingga pengambilan keputusan tepat pada sasaran.

\section{Menentukan Kriteria dan Sumber Data}

Peneliti menentukan kriteria-kriteria dari sistem pendukung keputusan metode menggunakan metode Simple Additive Weighting 
(SAW) dalam menetukan pemberian raskin, diantaranya kepemilikan Kartu Keluarga Sehat (KKS), penghasilan, tempat tinggal, pendidikan, pola makan, dan kemampuan berobat. Kemudian menentukan data-data yang dibutuhkan berdasarkan populasi, sampel dan cara pengambilan sampel. Kemudian menentukan objek penelitian dan mempersiapkan alat pengumpulan data dengan menentukan dan menyusun alat ukur atau instrument penelitian yang akan digunakan dalam penelitian ini yaitu berupa skala model guttman.

6. Observasi Lapangan dan Perijinan

Peneliti secara langsung datang ke salah satu lingkungan Rukun Tetangga, yaitu RT.04 RW.01 di Depok dan meminta ijin kepada pihak-pihak terkait dan berwenang.

\section{Mengumpulkan Data}

Peneliti mengumpulkan data-data dan melakukan wawancara mengenai hal- hal yang berkaitan dengan penlitian.

\section{Analisis Data}

Peneliti menganalisa dan mengolah data quesioner, serta menentukan bobot- bobot dari masing-masing kriteria.

\section{Menarik Kesimpulan}

Peneliti mengambil suatu kesimpulan berdasarkan analisis data-data yang terdapat pada bab-bab sebelumnya dan diperiksa apakah kesimpulan sesuai dengan hipotesis, maksud dan tujuan penelitian. Selain itu juga memberikan saran yang dapat digunakan sebagai masukan bagi pengurus RT terkait untuk dapat dimanfaatkan lebih lanjut.

\section{B. Instrument Penelitian}

Adapun jenis instrument yang digunakan dalam penilitian ini, yaitu ;

\section{a. Observasi}

Metode ini diterapkan dengan mendatangi obyek lingkungan Rukun Tetangga, yaitu salah satu pengurus RT.04/01 di Depok untuk mendapatkan data-data yang dibutuhkan.

\section{b. Wawancara}

Pengumpulan data dengan cara wawancara adalah suatu usaha untuk mengumpulkan informasi dengan mengajukan beberapa pertanyaan secara lisan kepada pengurus RT.04/01.

\section{c. Studi Pustaka}

Metode ini dilaksanakan dengan melakukan studi kepustakaan melalui membaca buku-buku, jurnal penelitian sejenis e-book yang dapat mendukung penulisan skripsi ini, yaitu yang menjelaskan tetntang Sistem Pendukung Keputusan (SPK) dengan menggunakan metode Simple Additive Weighting (SAW).

\section{d. Quesioner}

Pengumpulan data dengan cara mengumpulkan angket yang telah diisi oleh narasumber yang bertujuan untuk mendapatkan data yang akan digunakan dalam penerapan Metode Simple Additive Weghting.

\section{Metode Pengumpulan Data, Populasi dan Sampel Penelitian}

1. Metode Pengumpulan Data

Metode pengumpulan data yang dilakukan peneliti terbagi menjadi 2 cara, yaitu:

a. Dengan melakukan observasi langsug, wawancara, dan questioner untuk mendapatkan data primer.

b. Data sekunder berasal dari mengumpulkan dan mengidentifikasi serta mengolah data tertulis berbentuk buku-buku dan jurnal yang berkaitan dengan penilitian.

2. Populasi dan Sampel Penelitian

Menurut Sugiyono (2008: 80) "Populasi adalah wilayah generalisasi yang terdiri: obyek/subyek yang mempunyai kualitas dan karakteristik tertentu yang ditetapkan oleh penenliti untuk dipelajari dan kemudian ditarik kesimpulannya." Menurut Sugiyono (2008: 81) "Teknik sampling adalah teknik pengambilan sampel. Untuk menentukan sampel yang akan digunakan dalam penelitian."

Dalam Penelitian ini, peneliti melakukan observasi dan wawancara langsung kepada pengurus RT.04 RW.01 di Depok. Populasi yang diambil adalah warga sebanyak 50 orang. Dari populasi tersebut akan diambil 42 sampel.

\section{HASIL PENELITIAN DAN PEMBAHASAN}

Tabel dibawah merupakan isi kuisioner dimana setiap item instrumen nilai tersebut diambil dari skala rating.

Tabel 1. Variabel skala kriteria

\begin{tabular}{cllllll}
\hline No & DATA & C1 & C2 & C3 & C4 & C5 \\
\hline 1 & Aryana & SB & SB & SB & TB & SB \\
\hline 2 & Henandar & TB & SB & SB & TB & SB \\
\hline
\end{tabular}




\begin{tabular}{|c|c|c|c|c|c|c|}
\hline No & DATA & C1 & $\mathrm{C} 2$ & $\mathrm{C} 3$ & $\mathrm{C} 4$ & $\mathrm{C} 5$ \\
\hline 3 & Karmadi & SB & SB & SB & $\mathrm{TB}$ & SB \\
\hline 4 & Miftahudin & TB & SB & SB & TB & SB \\
\hline 5 & Malik & TB & SB & SB & SB & SB \\
\hline 6 & Rendi & TB & SB & SB & SB & SB \\
\hline 7 & Kartija & TB & SB & SB & $\mathrm{TB}$ & SB \\
\hline 8 & Delfi Efendi & SB & SB & SB & TB & SB \\
\hline 9 & Deni & TB & SB & SB & SB & SB \\
\hline 10 & Gunarso & TB & SB & SB & $\mathrm{TB}$ & SB \\
\hline 11 & Sunandar & TB & SB & SB & $\mathrm{TB}$ & SB \\
\hline 12 & Bram & SB & SB & SB & $\mathrm{TB}$ & SB \\
\hline 13 & Deden & SB & SB & TB & $\mathrm{TB}$ & SB \\
\hline 14 & Agus & TB & TB & $\mathrm{TB}$ & $\mathrm{TB}$ & SB \\
\hline 15 & Munawar & SB & SB & TB & TB & SB \\
\hline 16 & Abdul Majid & TB & TB & SB & SB & SB \\
\hline 17 & Suryani & SB & SB & TB & TB & SB \\
\hline 18 & Sairin & TB & TB & SB & TB & SB \\
\hline 19 & Heriansyah & TB & SB & SB & SB & SB \\
\hline 20 & Ayat & TB & SB & TB & TB & SB \\
\hline 21 & Jaka Wahyudin & TB & SB & TB & TB & SB \\
\hline 22 & Amran & TB & TB & TB & $\mathrm{TB}$ & SB \\
\hline 23 & Subeki & TB & SB & SB & SB & SB \\
\hline 24 & Syahroni & TB & TB & SB & SB & SB \\
\hline 25 & M Idris & TB & SB & TB & SB & SB \\
\hline 26 & Sukriyah & SB & SB & SB & SB & SB \\
\hline 27 & Sarinah & SB & SB & SB & SB & SB \\
\hline 28 & Imbron & TB & TB & TB & SB & SB \\
\hline 29 & Dimas & SB & TB & SB & $\mathrm{TB}$ & SB \\
\hline 30 & Zarkoni & SB & SB & SB & TB & SB \\
\hline 31 & Bambang S R & SB & SB & TB & TB & SB \\
\hline 32 & Ridwan & SB & SB & SB & TB & SB \\
\hline 33 & Adi Gunawan & SB & SB & TB & TB & SB \\
\hline 34 & Marhadi & SB & SB & SB & $\mathrm{TB}$ & SB \\
\hline 35 & Nenih & SB & SB & SB & TB & SB \\
\hline 36 & Udin & SB & SB & $\mathrm{TB}$ & $\mathrm{TB}$ & SB \\
\hline 37 & Mat Amin & SB & SB & TB & $\mathrm{TB}$ & SB \\
\hline 38 & Homsyah & SB & SB & SB & TB & SB \\
\hline 39 & Yati Aryati & SB & SB & SB & TB & SB \\
\hline 40 & Dian jauhari & SB & TB & TB & $\mathrm{TB}$ & SB \\
\hline 41 & Oktorizal & SB & SB & $\mathrm{TB}$ & SB & SB \\
\hline 42 & Toriq & SB & TB & TB & TB & SB \\
\hline
\end{tabular}

\section{Data Matrik X}

Tabel dibawah ini merupakan data matriks dimana setiap kriteria didapat dari rekap kuisioner diubah ke bilangan fuzzy berdasarkan nilai bobot yang telah ditentukan.

Tabel 2. Matriks Persamaan

\begin{tabular}{clccccc}
\hline \multirow{2}{*}{ No } & \multirow{2}{*}{ Data } & \multicolumn{5}{c}{ Matriks Bobot Fuzzy } \\
\cline { 3 - 7 } & & C1 & C2 & C3 & C4 & C5 \\
\hline 1 & Aryana & 1 & 1 & 1 & 0.25 & 1 \\
\hline 2 & Henandar & 0,25 & 1 & 1 & 0.25 & 1 \\
\hline 3 & Karmadi & 1 & 1 & 1 & 0.25 & 1 \\
\hline 4 & Miftahudin & 0.25 & 1 & 1 & 0.25 & 1 \\
\hline 5 & Malik & 0.25 & 1 & 1 & 1 & 1 \\
\hline 6 & Rendi & 0.25 & 1 & 1 & 1 & 1 \\
\hline 7 & Kartija & 0.25 & 1 & 1 & 0.25 & 1 \\
\hline 8 & Delfi & 1 & 1 & 1 & 0.25 & 1 \\
& Efendi & & & & & \\
\hline 9 & Deni & 0.25 & 1 & 1 & 1 & 1 \\
\hline 10 & Gunarso & 0.25 & 1 & 1 & 0.25 & 1 \\
\hline 11 & Sunandar & 0.25 & 1 & 1 & 0.25 & 1 \\
\hline 12 & Bram & 1 & 1 & 1 & 0.25 & 1 \\
\hline 13 & Deden & 1 & 1 & 0.25 & 0.25 & 1 \\
\hline 14 & Agus & 0.25 & 0.25 & 0.25 & 0.25 & 1 \\
\hline & & & & & & \\
\hline
\end{tabular}

\begin{tabular}{|c|c|c|c|c|c|c|}
\hline \multirow{2}{*}{ No } & \multirow{2}{*}{ Data } & \multicolumn{5}{|c|}{ Matriks Bobot Fuzzy } \\
\hline & & C1 & $\mathrm{C} 2$ & $\begin{array}{ll}\mathrm{C} 3 \\
\mathrm{n}\end{array}$ & $\mathrm{C} 4$ & $\mathrm{C} 5$ \\
\hline 15 & Munawar & 1 & 1 & 0.25 & 0.25 & 1 \\
\hline 16 & $\begin{array}{l}\text { Abdul } \\
\text { Majid }\end{array}$ & 0.25 & 0.25 & 1 & 1 & 1 \\
\hline 17 & Suryani & 1 & 1 & 0.25 & 0.25 & 1 \\
\hline 18 & Sairin & 0.25 & 0.25 & 1 & 0.25 & 1 \\
\hline 19 & Heriansyah & 0.25 & 1 & 1 & 1 & 1 \\
\hline 20 & Ayat & 0.25 & 1 & 0.25 & 0.25 & 1 \\
\hline 21 & $\begin{array}{l}\text { Jaka } \\
\text { Wahyudin }\end{array}$ & 0.25 & 1 & 0.25 & 0.25 & 1 \\
\hline 22 & Amran & 0.25 & 0.25 & 0.25 & 0.25 & 1 \\
\hline 23 & Subeki & 0.25 & 1 & 1 & 1 & 1 \\
\hline 24 & Syahroni & 0.25 & 0.25 & 1 & 1 & 1 \\
\hline 25 & M Idris & 0.25 & 1 & 0.25 & 1 & 1 \\
\hline 26 & Sukriyah & 1 & 1 & 1 & 1 & 1 \\
\hline 27 & Sarinah & 1 & 1 & 1 & 1 & 1 \\
\hline 28 & Imbron & 0.25 & 0.25 & 0.25 & 1 & 1 \\
\hline 29 & Dimas & 1 & 0.25 & 1 & 0.25 & 1 \\
\hline 30 & Zarkoni & 1 & 1 & 1 & 0.25 & 1 \\
\hline 31 & $\begin{array}{l}\text { Bambang S } \\
\text { R }\end{array}$ & 1 & 1 & 0.25 & 0.25 & 1 \\
\hline 32 & Ridwan & 1 & 1 & 1 & 0.25 & 1 \\
\hline 33 & $\begin{array}{l}\text { Adi } \\
\text { Gunawan }\end{array}$ & 1 & 1 & 0.25 & 0.25 & 1 \\
\hline 34 & Marhadi & 1 & 1 & 1 & 0.25 & 1 \\
\hline 35 & Nenih & 1 & 1 & 1 & 0.25 & 1 \\
\hline 36 & Udin & 1 & 1 & 0.25 & 0.25 & 1 \\
\hline 37 & Mat Amin & 1 & 1 & 0.25 & 0.25 & 1 \\
\hline 38 & Homsyah & 1 & 1 & 1 & 0.25 & 1 \\
\hline 39 & Yati Aryati & 1 & 1 & 1 & 0.25 & 1 \\
\hline 40 & $\begin{array}{l}\text { Dian } \\
\text { jauhari }\end{array}$ & 1 & 0.25 & 0.25 & 0.25 & 1 \\
\hline 41 & Oktorizal & 1 & 1 & 0.25 & 1 & 1 \\
\hline 42 & Toriq & 1 & 0.25 & 0.25 & 0.25 & 1 \\
\hline Per & itungan $\mathrm{A}$ & & & & & \\
\hline$r_{i}=$ & $\begin{array}{l}\frac{x_{i j}}{\operatorname{Max} X_{i j}} j i k a j a \\
\frac{\operatorname{Min} X_{i j}}{x_{i j}} j i k a j a\end{array}$ & hat & & $\begin{array}{l}\text { an }(b \\
\text { st) } X i j\end{array}$ & & ...(1) \\
\hline
\end{tabular}

Dimana dengan rij adalah rating kinerja ternormalisasi dari alternatif $\mathrm{Ai}$ pada atribut $\mathrm{Cj}: \mathrm{i}=$ $1,2 \ldots, \mathrm{m}$ dan $\mathrm{j}=1,2 \ldots, \mathrm{n}$

Keterangan :

Max Xij = Nilai terbesar dari setiap kriteria $\mathrm{i}$

Min Xij = Nilai terbesar dari setiap kriteria $\mathrm{i}$.

$\mathrm{X}$ ij = Nilai atribut yang dimiliki dari setiap kriteria.

Benefit = Jika nilai terbesar adalah terbaik.

Cost = Jik nilai terkecil adalah terbaik. 


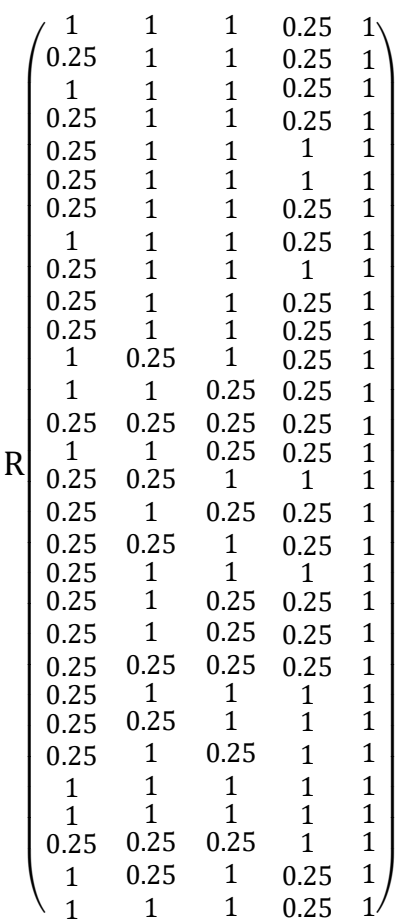

Normalisasi R

$\mathrm{R}=\left(\begin{array}{ccccc}1 & 1 & 0.25 & 0.25 & 1 \\ 1 & 1 & 1 & 0.25 & 1 \\ 1 & 1 & 0.25 & 0.25 & 1 \\ 1 & 1 & 1 & 1 & 1 \\ 1 & 1 & 1 & 0.25 & 1 \\ 1 & 1 & 0.25 & 0.25 & 1 \\ 1 & 1 & 0.25 & 0.25 & 1 \\ 1 & 1 & 1 & 0.25 & 1 \\ 1 & 1 & 1 & 0.25 & 1 \\ 1 & 0.25 & 0.25 & 0.25 & 1 \\ 1 & 1 & 0.25 & 1 & 1 \\ 1 & 0.25 & 0.25 & 0.25 & 1\end{array}\right)$

Hasil dari normalisasi diatas selanjutnya dikalikan dengan bobot kriteria sesuai jenjangnya :

Bobot Vektor $=[1: 0,75: 0,5: 0,25: 0,25]$

Hasil Vektor

$V_{i}=\sum_{j=1}^{n} w_{j} r_{i j}$

Nilai Preferensi untuk setiap alternatif (Vi) diberikan rumus sebagai berikut, Dimana:

$\mathrm{Vi}=$ Rangking untuk setiap alternatif.

$\mathrm{Wj}=$ Nilai bobot rangking (dari setiap kriteria). rij = Nilai rating kinerja ternormalisasi.

Berdasarkan hipotesis pengambilan keputusan dengan menggunakan Simple Additive Weighting (SAW) akan memberikan alternative keputusan yang baik bagi pengurus RT.04 RW.01 sehingga pengambilan keputusan tepat pada sasaran. Hasil penelitian dari metode Simple Additive Weighting (SAW) yang telah diperhitungkan dapat disimpulkan bahwa pemberian raskin diberikan kepada dengan hasil

Tabel 3. Tabel Rangking

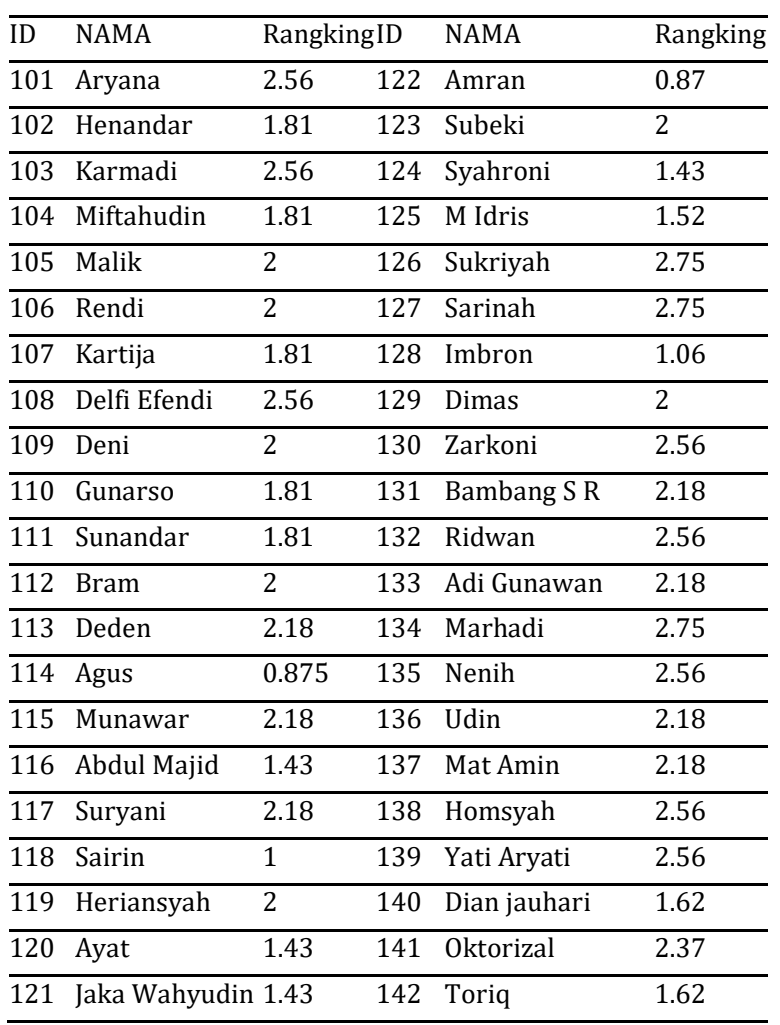

Tabel 4. Tabel rangking terbaik

\begin{tabular}{cccccccc}
\hline Id & No & Nama & Rangking & Id & No & Nama & Rangking \\
\hline 126 & 1 & Sukriyah & 2.75 & 136 & 16 & Udin & 2.18 \\
\hline 127 & 2 & Sarinah & 2.75 & 137 & 17 & Mat Amin & 2.18 \\
\hline 134 & 3 & Marhadi & 2.75 & 105 & 18 & Malik & 2 \\
\hline 101 & 4 & Aryana & 2.56 & 106 & 19 & Rendi & 2 \\
\hline 103 & 5 & Karmadi & 2.56 & 109 & 20 & Deni & 2 \\
\hline 108 & 6 & Delfi Efendi & 2.56 & 112 & 21 & Bram & 2 \\
\hline 130 & 7 & Zarkoni & 2.56 & 119 & 22 & Heriansyah & 2 \\
\hline 132 & 8 & Ridwan & 2.56 & 123 & 23 & Subeki & 2 \\
\hline 138 & 9 & Homsyah & 2.56 & 129 & 24 & Dimas & 2 \\
\hline 139 & 10 & Yati Aryati & 2.56 & 102 & 25 & Henandar & 1.81 \\
\hline 141 & 11 & Oktorizal & 2.37 & 104 & 26 & Miftahudin & 1.81 \\
\hline 113 & 12 & Deden & 2.18 & 110 & 27 & Gunarso & 1.81 \\
\hline 117 & 13 & Suryani & 2.18 & 111 & 28 & Sunandar & 1.81 \\
\hline 131 & 14 & Bambang S & 2.18 & 140 & 29 & Dian jauhari & 1.62 \\
\hline 133 & 15 & Adi & 2.18 & 142 & 30 & Toriq & 1.62 \\
\hline
\end{tabular}




\section{KESIMPULAN}

Berdasarkan hasil penelitian dan pembahasan dapat diambil kesimpulan bahwa sistem pendukung keputusan ini dibangun utuk membantu dalam pemberian raskin dilingkungan RT.04 RW.01 Sukmajaya Depok dengan menggunakan metode, yaitu metode Simple Additive Weighting (SAW) yang dapat mempercepat proses menentukan pemberian raskin dengan perhitungan yang akurat. Hasil penelitian dari metode Simple Additive Weighting (SAW) yang telah diperhitungkan dapat disimpulkan bahwa pemberian Raskin diberikan kepada Sukriyah dengan hasil 2.75. Penelitian dapat dikembangkan lebih lanjut dengan krtiria-kriteria yang berbeda sesuai dengan kriteria dan bobot yang ditentukan untuk menyelesaikan permasalan-permasalahan sosial lainnya.

\section{REFERENSI}

Angrawati, D., Angrawati, D., Yamin, M., \& Ransi, N. (2016). SISTEM PENDUKUNG KEPUTUSAN MENENTUKAN JUMLAH BERAS MISKIN MENGGUNAKAN METODE SIMPLE ADDITIVE WEIGHT (SAW). SemanTIK, 2(1). Retrieved from http://ojs.uho.ac.id/index.php/semantik/arti cle/view/712

Handayani, H. (2016). SISTEM PENDUKUNG KEPUTUSAN UNTUK PENERIMAAN RASKIN (BERAS MISKIN) DI DESA TANGGUL KUNDUNG MENGGUNAKAN METODE SAW. Kediri. Retrieved from http://simki.unpkediri.ac.id/mahasiswa/file_ artikel/2016/11.1.03.03.0117.pdf

Marlaeni, N. U., \& Satria, F. (2017). SISTEM PENDUKUNG KEPUTUSAN UNTUK MENENTUKAN PENERIMA RASKIN (BERAS UNTUK RAKYAT MISKIN) MENGGUNAKAN
METODE SAW (Studi Kasus: Desa Cabang Empat Kec. Abung Selatan Kab. Lampung Utara). PROCIDING KMSI, 5(1). Retrieved from

http://ojs.stmikpringsewu.ac.id/index.php/p rocidingkmsi/article/view/450

Rini, A. S., \& Soyusiawaty, D. (2014). SISTEM PENDUKUNG KEPUTUSAN SELEKSI PENERIMAAN BERAS UNTUK KELUARGA MISKIN DENGAN METODE SIMPLE ADDITIVE WEIGHTING. JSTIE (Jurnal Sarjana Teknik Informatika) (E-Journal), 2(2), 121130.

https://doi.org/10.12928/JSTIE.V2I2.2728

Septian, M. D., Bahri, T. S., \& Makmur, T. (2013). Analisis Efektivitas Dan Efisiensi Distribusi Beras Miskin (Raskin) Di Kecamatan Trienggadeng Kabupaten Pidie Jaya. Jurnal Agrisep, 14(1), 70-78. Retrieved from http://www.jurnal.unsyiah.ac.id/agrisep/art icle/view/910

Suryeni, E., Agustin, Y. H., \& Nurfitria, Y. (2015). Sistem Pendukung Keputusan Kelayakan Penerimaan Bantuan Beras Miskin Dengan Metode Weighted Product Di Kelurahan Karikil Kecamatan Mangkubumi Kota Tasikmalaya. Proceedings Konferensi Nasional Sistem Dan Informatika (KNS\&I), O(0). Retrieved from http://ejournal.stikombali.ac.id/index.php/knsi/article/view/488

Widiarsih, D. (1974). Pengaruh Sektor Komoditi Beras Terhadap Inflasi Bahan Makanan. Jurnal Sosial Ekonomi Pembangunan, 2(6), 244-256. Retrieved from https://ejournal.unri.ac.id/index.php/JSEP/a rticle/view/863 